\title{
The Impact Of Demographic Variables On The Perceptions Of A Behavioral Safety Process In Manufacturing
}

Joy M. Jones, Smurfit - Stone Container Corporation, USA Robert C. Preziosi, Nova Southeastern University, USA

\begin{abstract}
This study examined safety perceptions of manufacturing employees involved in a safety behavioral modification process, and the perceptions of employees who are not involved in the same process, based on the idea that such a process helps to decrease injuries in the workplace. The Neal-Griffin Safety Climate/Safety Performance Instrument was used in a specific workplace to determine if race, gender, and age affect employees' perceptions of safety in an industrial/manufacturing setting. The results of this quantitative study found that, overall, the vast majority of the workers, regardless of demographic group membership, provided relatively high survey ratings, which indicate that they had positive perceptions regarding their company's safety procedures and miscellaneous safety issues.
\end{abstract}

Keywords: Behavior modification, industrial safety.

\section{INTRODUCTION}

1

n industrial America, safety and health issues are a major concern for company management as well as for stakeholders. According to the National Safety Council (2006), the cost of accidents in the United States reached an estimated 142.2 billion dollars in 2004. Forty-one fatal injuries to workers were reported in manufacturing in 2004-2005, an increase of 37\% over 2003-2004, after numbers had fallen in each of the previous four years. According to Gray, Myers, and Myers (1998), the cost of workers' compensation and health care benefits, the long-tailed effect of exposure to health hazards, the premature loss of future years of employment, and the prevention of human suffering are some of the reasons for this concern. Consequently, industry is increasingly coming to recognize the need to manage safety on a proactive basis in order to improve the safety for individuals at work and prevent significant financial loss (Frick, Jensen, Quinlan, \& Wilthangen, 2000; Parker, Axtell \& Turner, 2001).

In an effort to reduce work-related injuries, many organizations have implemented Behavior Based Safety processes. Gadd and Collins (2002) surmise that behavioral theory focuses on the main behaviors that lead to accidents rather than the accidents themselves, which are relatively infrequent and difficult to investigate objectively, or attitudes toward safety which are difficult to change. A key ingredient of every effective Behavior Based Safety intervention is observation and feedback, (Geller, Boyce, Williams, Pettinger, DePasquale, \& Clarke, 1998).

Behavior Based Safety processes can put the emphasis on the safety behavior of the worker rather than addressing the safety culture of the organization (Gadd \& Collins, 2002). Although the employee is trained on safe behaviors (for example, what to do if a machine gets stuck), if the safety culture of the company puts production pressures over safety that employee may still try to fix the machine rather than follow the correct procedure of waiting for maintenance to fix it (Atkinson, 2000). 


\section{WORKPLACE FATALITIES AND INJURIES}

According to the 1997 census of fatal occupational injuries, between 6,000 and 6,600 workers have been fatally injured each year since 1992, with highway fatalities being the leading cause of job-related deaths and violence in the workplace being the second leading cause of job-related deaths. Emmet (1991) claimed that, in the U.S. alone, approximately 65,000 chemicals are used in business and approximately 700 new ones are introduced into the workplace each year. Baker and Landrigan (1990) identified more that 35 different illnesses, their causal agent, and the industries where they are found.

In the last few years, more attention has also been paid to other workplace perils that seem to be increasing: (a) ergonomic hazards related to musculoskeletal problems (Bruening, 1997; Finnegan, 1997; Skov, Borg, \& Orheda, 1996); (b) respiratory diseases such as tuberculosis (Hooten, 1997); (c) and increasing rates of fatal pneumonoconiosis lung diseases from crystalline silica, coal dust, and asbestos, work related asthma, and exposure to "nuisance dust" (Figura, 1997).

\section{PURPOSE OF THE STUDY}

The purpose of this study is to examine safety perceptions of manufacturing employees who work in an environment that has implemented a safety behavioral modification process and an environment that has not implemented a safety behavioral modification process, based on the idea that such a process helps to decrease injuries in the workplace.

\section{THEORY BEING TESTED}

The conceptual framework for this study is derived from Homer and Kahle's (1978) value-attitudebehavior theory and Ajzen's (1991) theory of planned behavior. The value-attitude-behavior theory can be described as a function of attitude, which, in turn, is a consequence of an individual's value system (Homer \& Kahle, 1988). According to Johnson (2003), this model has been validated on several occasions, most notably in the field of consumer research. Because of the validity of the research in the area of consumer research, voter values, and behavior, the Homer and Kahle model links values, attitudes, and behaviors to provide an affective theory, but it does not provide cause and effect, only influence (Johnson, 2003).

\section{RESEARCH QUESTION AND HYPOTHESES}

The following research question and hypotheses is proposed: Does race, gender, and years of service positively impact industrial employees' perceptions of a behavioral safety modification process?

H1 Null = There is no positive increase in industrial employees' perception of safety by race when a behavioral safety modification process is in place in an industrial setting.

H1 = There is a positive increase in industrial employees' perception of safety by race when there is a behavioral safety modification process in place in an industrial setting.

H2 Null = There is no positive increase in industrial employees' perception of safety by gender when a behavioral safety modification process is in place in an industrial setting.

$\mathbf{H 2}=$ There is a positive increase in industrial employees' perception of safety by gender when a behavioral safety modification process is in place in an industrial setting.

H3 Null = There is no positive increase in industrial employees' perception of safety by years of service when a behavioral safety modification process is in place in an industrial setting.

H3 = There is a positive increase in industrial employees' perception of safety by years of service when a behavioral safety modification process is in place in an industrial setting. 


\section{DEFINITION OF TERMS}

Behavior: Acts or actions by individuals that can be observed by others.

Behavioral Safety Modification: A focus on systematically studying the effects of various interventions on target behaviors, first by defining the target behavior in a directly observable and recordable way, and second by observing and recording behavior in its natural setting (Geller, et. al., 1998).

Occupational Safety and Health Administration (OSHA): A division of the U.S. Department of Labor that oversees all federal regulations and guidelines in reference to workplace safety and occupational illnesses under the Occupation Safety and Health Act of 1970.

Organizational Culture: The "programming of the mind that distinguishes the members of one organization from another" (Hofstede, 1991, p.262).

Perceptions: Receiving, collecting, action of taking possession, apprehension with the mind or senses, to understand, to feel, or observe (Webster's Dictionary, 2005).

Safety Attitude: How a person feels or their state of mind about safety.

Safety Climate: The perceptions of policies, procedures, and practices relating to safety in the workplace.

Safety Culture: The product of individual and group values, attitudes, perceptions, competencies and patterns of behavior that determine the commitment to, and the style of proficiency of an organization's health and safety management (ACSNI, 1993).

\section{DEFINING AN ORGANIZATION}

Morgan (1986, 1997) noted that Frederick Taylor's Scientific Management theory was the dominant guide for organizing the modern bureaucracy. While perhaps undeserved, Taylor was regarded as an "enemy of the working man" at the time of his death in 1915. His virtue was the result of his willingness to expand the mechanistic approach by advocating the placement of the responsibility of running organizations into the hands of management.

Various cultures may be embedded in the groups that make up an organization (Smircich, 1983; Schein, 1984, 1985; Schein \& Ott, 1962). Smircich, therefore, noted the likelihood that multiple organizational subcultures, or even counter cultures, may exist and must not be neglected. Organizations are composed of subcultures, which may be mutually antagonistic as they compete (overtly and covertly) as different groups of organizational members seek to establish or impose their distinctive systems and definitions of reality (Johnson \& Gill, 1993). A very familiar subculture that organizations focus on is a component of organizational culture known as "safety culture".

\section{THEORETICAL DEVELOPMENT OF SAFETY CULTURE CONCEPT}

The safety culture of an organization is the product of individual and group values, attitudes, perceptions, competencies and patterns of behavior that determine the commitment to, and the style and proficiency of, an organization's health and safety management (ACSNI, 1993). Guldenmund (2000) defines safety culture as those aspects of the organizational culture which will impact those attitudes and behaviors related to increasing or decreasing risk. According to Hale (2000), safety culture entails the attitudes, beliefs and perceptions shared by natural groups as the defining norms and values which determine how they act and react. Although many definitions exist for the term "safety culture", common threads can be found throughout.

Much empirical research has focused on safety climate or on safety attitudes as the "most important" aspect of safety culture. Like organizational culture, safety culture might be defined as representing the basic values, beliefs and assumptions concerning safety that are embedded in the organization. This reflects our original understanding of the concept "a corporate atmosphere or culture in which safety is understood to be accepted as the number one 
priority" (Cullen, 1990, p. 300). At its deepest level, safety culture might simply be understood as putting safety first. organizational structures and practices (Schwartz \& Davis, 1981).

\section{SAFETY CLIMATE}

Safety climate can be understood as the subjective perception of organizational members as to the condition of their working environment. It is defined by Zohar (1980) as "a summary of molar perceptions that employees share about their work environments" (p. 96). Moran and Volkwein (1992) suggest that climate formation is dependent on individual perceptions, interactions between group members, and also the impact of organizational culture. The work climate (related to safety) acts as a frame of reference for safety-related work behaviors.

To date, safety climate literature has tended to focus on two major issues: (a) the factor structure of safety climate and (b) the relationship between safety climate and outcome variables. A number of different measures of safety climate have been developed by researchers working in this field (Cox \& Cheyne, 2000; Hayes, Peranda, Smecko \& Trask, 1998; Zohar, 1980). Unfortunately, these measures have produced a wide range of different structures, and no consensus currently exists regarding the key dimensions of safety climate.

\section{ATTITUDES}

The literature suggests that safety attitudes are empirically related to measures of safety performance. However, some confusion exists regarding the relationship between safety attitudes, safety climate and safety culture, and the mechanisms linking these concepts to safety outcomes.

Personal beliefs about risk and safety, personal involvement, individual responsibility, evaluations of safety measures, and evaluation of work environment can be summarized as "safety attitudes" and the physical hazards of the workplace. Cox and Cox (1991) investigated the architecture of "safety attitudes" towards safety software, and people and risk. They found five dimensions (a) personal skepticism, (b) individual responsibility, (c) safeness of work environment, (d) effectiveness of arrangements for safety, and (e) personal immunity. The researchers describe individual responsibility (constructive beliefs), personal skepticism and immunity (both unconstructive beliefs) as personal beliefs about risk and safety; while safeness of the work environment and effectiveness of arrangements for safety are both evaluations. Cheyne et al. (1998) measured the physical work environment (basic environment work conditions: lighting, ventilation, working space, humidity), physical hazards and attitudes to safety. Factor analysis of attitudes to safety found five dimensions: (a) safety management, (b) communication, (c) individual responsibility, (d) safety standards and goals, and (e) personal involvement.

\section{BEHAVIORAL SAFETY MODIFICATION}

Behavior based approaches to safety have a number of advantages. They (a) can be administered by individuals with minimal professional training, (b) can reach people in the setting where a problem occurs (community, school, workplace), and (c) the leaders in these settings can be taught the behavioral techniques most likely to work under specific circumstances (Geller et.al,1998). This approach to safety focuses on systematically studying the effects of various interventions on target behaviors by defining the target behavior in a directly observable and recordable way.

When attempting to define safe behavior, the definition must have the capability of being both qualitative and quantitative given that the behavioral approach to safety is a measurable process. In other words, safe behavior must be defined in a manner that allows for the collection of data (Johnson, 2003).

An intervention can be implemented when a stable baseline of the frequency, rate, or duration of a specific behavior is obtained. Unfortunately, most safety programs spend a significant amount of time and resources on what could be termed attitude adjustment measures. For example, poster and safety slogan contests, meetings, training and other efforts are used to improve attitudes and to increase awareness. Krause and Sloat (1993) state that by structuring training and other safety efforts around ongoing soon-certain-positive consequences that focus attitudes 
on identified critical behaviors, management can assure that workforce safety attitudes reliably predict safe behaviors.

When considering the link between attitude and behavior, three points must be considered: (1) There must be consequences for behavior, (2) behavior can be measured, and (3) antecedents of behavior include attitudes, but are not limited to just attitude. According to Krause and Sloat (1993), a behavior based approach to safety should include: (a) Developing action plans that are directed at soon-certain-positive consequences for improved safety performance, (b) the primary focus of improvement is behavior, which can be measured and managed, versus attitude, and (c) assessments of existing antecedents take into account their full range, giving safety attitude its proper due as one of the antecedents of safety related behavior.

\section{FEEDBACK}

One of the most powerful consequences for behavioral change is providing feedback on performance (Mills, 1996). According to Chhockar and Wallin (1984), feedback is perhaps one of the most dependable and thoroughly-tested principles in modern day psychology for improving performance (Ammons, 1956; Annett, 1969; Sassenrath, 1975). Behavioral programs, particularly those employing non-monetary consequences such as feedback, have been found effective as motivational strategies and readily acceptable to employees and employers (Komaki, Heinzmann, \& Lawson, 1980). Established procedures, demonstrations, written standards and extensive training help to relay the level of desired performance. Feedback can then be provided after the desired or undesired performance.

\section{METHODOLOGY}

In this study, a quantitative method of research using inferential statistical procedures will be utilized to investigate whether perceptions of safety in an industrial environment are more positive when a behavioral safety modification process is present within the safety management system, compared to an industrial setting that does not include a behavioral safety modification process. Regression and factorial analysis of variance (ANOVA) will be used to determine the degree to which race, gender, and years of service.

\section{POPULATION AND SAMPLE}

The participants for this study are employees of a corrugated container company, with three locations in metropolitan Atlanta, Georgia. Salaried, hourly, union and non-union employees will participate in the survey. A convenience sample taken from the same company, but different sites, was divided into a subset from one facility where a Behavioral Safety Modification Process existed for eight years (Covington, GA, N = 103) and a subset from two other facilities where there was no existing Behavioral Safety Modification Process ( Sheet Plant, $\mathrm{N}=33$ and East Plant, $\mathrm{N}=103$ ).

\section{INSTRUMENTATION}

\section{Reliability}

The safety perception survey used for this research will be a perception survey developed by Andrew Neal of the University of Queensland, Australia and Mark Griffin of the Queensland University of Technology, Australia. Permission was obtained from Mr. Neal and Mr. Griffin prior to the use of this instrument. Neal and Griffin developed this instrument to measure perceptions of safety at work using 35 items from Hart, Griffin, Wearing and Cooper's (1996) Organizational Climate Scale. Private and public sector organizations have been assessed using this questionnaire with the results showing the instrument to be valid (Hart et al., 1996). 


\section{VALIDITY}

\section{Internal Validity}

Two separate studies have demonstrated that perceptions of safety climate can be differentiated from perceptions of knowledge and motivation, and from self-reported safety compliance and participation (Griffin \& Neal, 2000a; Neal, Griffin, \& Hart, 2000). Furthermore, these studies demonstrated that knowledge and motivation mediate the relationship between safety climate and self reported safety compliance and participation. Neal et al. (2000) also demonstrated that perceptions of safety climate were correlated with perceptions of general psychological climate and that safety climate mediated the relationship between general psychological climate and behavior. These findings suggest that general psychological climate provides a context in which individuals evaluate the safety of their work environment.

\section{External Validity}

Griffin and Neal (2000a) also examine the hierarchical structure of safety climate perceptions. James and James (1989) argue that individuals evaluate specific features of their work environment in terms if their personal values and the significance of those features for their overall well being. According to this argument, perceptions of different facets of the work environment should load onto a common higher order factor. Griffin and Neal (2000a), therefore, conclude that the different dimensions of safety climate should be conceptualized as first-order factors, which in turn should load onto a higher order factor. The first order factors should reflect perceptions of safetyrelated policies, procedures and practices, while the higher-order factor should reflect the extent to which employees believe that safety is valued in the organization. As predicted, Griffin and Neal (2000a) found that questions assessing perceptions of management values, safety communication, safety practices, safety training and safety equipment loaded onto five separate first-order factors, which in turn loaded onto a higher order factor.

\section{DATA COLLECTION}

Permission was given by the Regional Safety Manager to conduct the survey during quarterly information sharing meetings at a corrugated container company in metropolitan Atlanta, Georgia. The facility meetings were held in Lithonia, Georgia, and Covington, Georgia. Three separate meetings were held during the day of the meetings to accommodate the three shift operation in both plants, but on different days. Instructions were given to the employees at the quarterly meeting on how to complete the survey. It was made clear to all employees that the survey was optional and choosing not to participate would not affect their jobs. Surveys were then distributed to the employees attending each meeting. They were given 30 minutes to complete the survey.

\section{RESEARCH QUESTIONS}

The overriding research question is, does race, gender, and years of service positively impact industrial employees' perceptions of a behavioral safety modification process?

\section{RESULTS}

The goal of this quantitative research study was to examine industrial employees' perceptions of safety as a function of whether or not they work in an organization that has adopted a behavioral safety modification process and based on demographic factors such as race, gender, and years of service. Therefore, participants completed a quantitative five point Likert scale with a demographic section.

The independent variables in this study include whether or not employees work in an organization that has adopted a behavioral safety modification process and the demographic variables serve as intervening variables (i.e. mediators and moderators). The dependent variable is the overall perception of the employees' based on their overall score (i.e. mean score across all survey items) on the Safety Climate-Safety Performance Scales Survey. This remainder of this chapter is comprised of three sections including a discussion of the data preparation and analysis procedures, the results for each research hypothesis and an integrated summary of the results. 


\section{DATA PREPARATION AND ANALYSIS PROCEDURES}

The survey item responses were coded such that a value of one was assigned to a response of strongly disagree, disagree was coded as two, neutral was coded as three, agree was coded as four and strongly agree was coded as five. Due to the fact that Item 1 on the survey was negatively phrased, that item was reverse coded (strongly agree $=1$, etc.) prior to computing an overall survey perception score. The overall survey perception score was created by taking the average across all 22 items on the survey, which created a continuous, interval level score. However, instead of including the original Item 1 values, the reverse coded values were used when computing the overall survey score so that higher values were consistently associated with more positive perceptions.

An inter-item reliability analysis was conducted on all 22 survey items to assess the internal consistency of the survey. Cronbach's alpha was used to compute the inter-item reliability coefficient. The results of the reliability analysis indicate that the coefficient was very high $(\mathrm{r}=.95)$ and, therefore, the items are reliable and related the same underlying construct (i.e. employee perceptions of workplace safety).

The survey items were summarized using the mean, which is a measure of central tendency that provides a descriptive statistic of the sample average. Simple comparisons were made between the two safety groups (safety program vs. no safety program) for descriptive purposes only.

Inferential statistics were used to test the research hypotheses. Statistical significance was determined based on a significance value of .05 or less (i.e. $\mathrm{p} \leq .05$ ). Research hypotheses that contained categorical (i.e. nominal or ordinal) variables were analyzed using a factorial analysis of variance (ANOVA) since demographic categories were being compared. The factorial ANOVA tested for the main effect of safety group, the main effect of the demographic variable and the interaction between the two. The research hypothesis that contained a continuous variable (i.e. years of service) was addressed using multiple regression analysis. An interaction term was created for the regression model by multiplying the two predictor variables. Therefore, the regression analysis included three terms: (a) the effect of safety group, (b) the effect of years of service and (c) the interaction term.

Research hypothesis one was addressed using a 2 X 4 factorial ANOVA; two levels of group (safety/nonsafety) and four levels of race. Only one participant was characterized as "other" and was therefore not included in this particular analysis, which left the following races to be compared (a) Asians, (b) Blacks, (c) Whites and (d) Hispanics. The second research hypothesis was addressed using a 2 X 2 factorial ANOVA; two levels of group and two levels of gender. The third research hypothesis was analyzed using regression analysis in which group, years of service and the interaction term were included in the regression model.

\section{RESULTS}

Prior to testing each of the research hypotheses, the participants' responses to each survey item were summarized by group (safety/non-safety). The results were broken down into four separate tables due to the large number of items. The results for the first six items are provided in Table 1. The means for Item 1 which states, "There are significant dangers inherent in the workplace", are based on the original scale where a value of one represents a response of strongly disagree.

The results in Table 1 indicate that the two groups had relatively similar mean ratings. In some cases, the non-safety group provided higher mean ratings and in other cases the safety group provided higher mean ratings. In general, the two groups were most likely to agree with the statements. 
Table 1

Group Means for Items 1-6

\begin{tabular}{|c|c|c|c|}
\hline Source & Group & $N$ & Mean \\
\hline Significant dangers inherent in workplace & Safety & 106 & 3.77 \\
\hline Significant dangers inherent in workplace & No Safety & 70 & 3.89 \\
\hline Management considers safety important & Safety & 106 & 4.22 \\
\hline Management considers safety important & No Safety & 70 & 4.19 \\
\hline Employees receive comprehensive training & Safety & 106 & 3.97 \\
\hline Employees receive comprehensive training & No Safety & 70 & 3.91 \\
\hline I know how to perform my job safely & Safety & 106 & 4.32 \\
\hline I know how to perform my job safely & No Safety & 70 & 4.33 \\
\hline I help coworkers in risky or hazardous conditions & Safety & 106 & 4.08 \\
\hline I help coworkers in risky or hazardous conditions & No Safety & 70 & 4.17 \\
\hline I ensure highest levels of safety & Safety & 106 & 4.31 \\
\hline I ensure highest levels of safety & No Safety & 70 & 4.33 \\
\hline
\end{tabular}

Table 2 contains the summarized results for items 7-12. The results in Table 2 indicate that, again, the two groups had very similar mean ratings with the non-safety group yielding a slightly higher mean in some cases and vice versa. Also, the two groups were most likely to show general agreement with the items.

Table 2

Group Means for Items 7-12

\begin{tabular}{llll}
\hline Source & Group & $N$ & Mean \\
\hline I use the correct safety procedures & Safety & 106 & 4.32 \\
I use the correct safety procedures & No Safety & 70 & 4.31 \\
Safety procedures/practices are useful \& effective & Safety & 106 & 4.10 \\
Safety procedures/practices are useful \& effective & No Safety & 70 & 4.13 \\
I know how to maintain/improve workplace safety & Safety & 106 & 4.09 \\
I know how to maintain/improve workplace safety & No Safety & 70 & 4.11 \\
Training covers situations employees encounter & Safety & 106 & 4.00 \\
Training covers situations employees encounter & No Safety & 70 & 3.91 \\
Workplace health \& safety is an important issue & Safety & 106 & 4.35 \\
Workplace health \& safety is an important issue & No Safety & 70 & 4.41 \\
Safety procedures/practices are sufficient & Safety & 106 & 4.03 \\
Safety procedures/practices are sufficient & No Safety & 70 & 4.17 \\
\hline
\end{tabular}

The summarized results for Items 13-18 are presented in Table 3. The results in Table 3 follow the same general theme as the previous tables where participants were most likely to show general agreement regardless of 
group, the mean ratings of the two groups were similar and means were sometimes higher for the non-safety group and sometimes higher for the safety group.

Table 3

Group Means for Items 13-18

\begin{tabular}{llll}
\hline Source & Group & $N$ & Mean \\
\hline There are systematic procedures in place & Safety & 106 & 3.79 \\
There are systematic procedures in place & No Safety & 70 & 3.90 \\
I use all necessary safety equipment & Safety & 106 & 4.16 \\
I use all necessary safety equipment & No Safety & 70 & 4.26 \\
I know how to use safety equipment & Safety & 106 & 4.18 \\
I know how to use safety equipment & No Safety & 70 & 4.24 \\
Employees are able to discuss concerns & Safety & 106 & 3.90 \\
Employees are able to discuss concerns & No Safety & 70 & 3.79 \\
Management is concerned about worker safety & Safety & 106 & 4.04 \\
Management is concerned about worker safety & No Safety & 70 & 3.94 \\
Worthwhile to put in effort-personal safety & Safety & 106 & 4.18
\end{tabular}

Table 4 provides the summarized results for Items 19-22. The results in Table 4 indicate that once again, the means were very similar between the two groups, general agreement was found across all of the items regardless of the group and means were higher for the non-safety group in some cases and lower in other cases.

Table 4

Group Means for Items 19-22

\begin{tabular}{|c|c|c|c|}
\hline Source & Group & $N$ & Mean \\
\hline There is frequent communication about safety issues & Safety & 106 & 4.08 \\
\hline There is frequent communication about safety issues & No Safety & 70 & 3.93 \\
\hline I voluntarily carry out tasks/activities-improve safety & Safety & 106 & 3.93 \\
\hline I voluntarily carry out tasks/activities-improve safety & No Safety & 70 & 3.94 \\
\hline The physical work environment is safe & Safety & 106 & 3.75 \\
\hline The physical work environment is safe & No Safety & 70 & 3.74 \\
\hline Safety is given a high priority by management & Safety & 106 & 4.03 \\
\hline Safety is given a high priority by management & No Safety & 70 & 4.06 \\
\hline
\end{tabular}

Although the two groups had very similar means in most cases, some small differences between the means were found (i.e. absolute difference $\geq .10$ ). Table 5 provides a summary of the mean difference between the two 
groups for the items that yielded absolute differences $\geq .10$ ). Negative values indicate that the non-safety group provided a higher mean rating while positive values indicate that the safety group provided a higher mean rating.

The results in Table 5 indicate that the largest differences were found with regard to there being frequent communication about safety issues in the workplace (safety group had stronger agreement) and employees' believing that it is worthwhile to make an effort to maintain or improve their personal safety (non-safety group had stronger agreement). The remaining differences indicate that the safety group was in stronger agreement that employees are able to discuss their concerns about safety issues with line management while the non-safety group had stronger agreement that systematic procedures are in place for preventing breakdowns in workplace safety, significant dangers are inherent in the workplace and safety procedures and practices are sufficient to prevent incidents from occurring. However, as previously mentioned, both groups showed general agreement with all of the survey items.

Table 5

Mean Difference between Safety Groups

Source

Mean Difference

There are systematic procedures in place

Employees are able to discuss concerns

0.11

Significant dangers inherent in workplace

Safety procedures/practices are sufficient

$-0.14$

There is frequent communication about safety issues

0.16

Worthwhile to put in effort-personal safety

$-0.16$

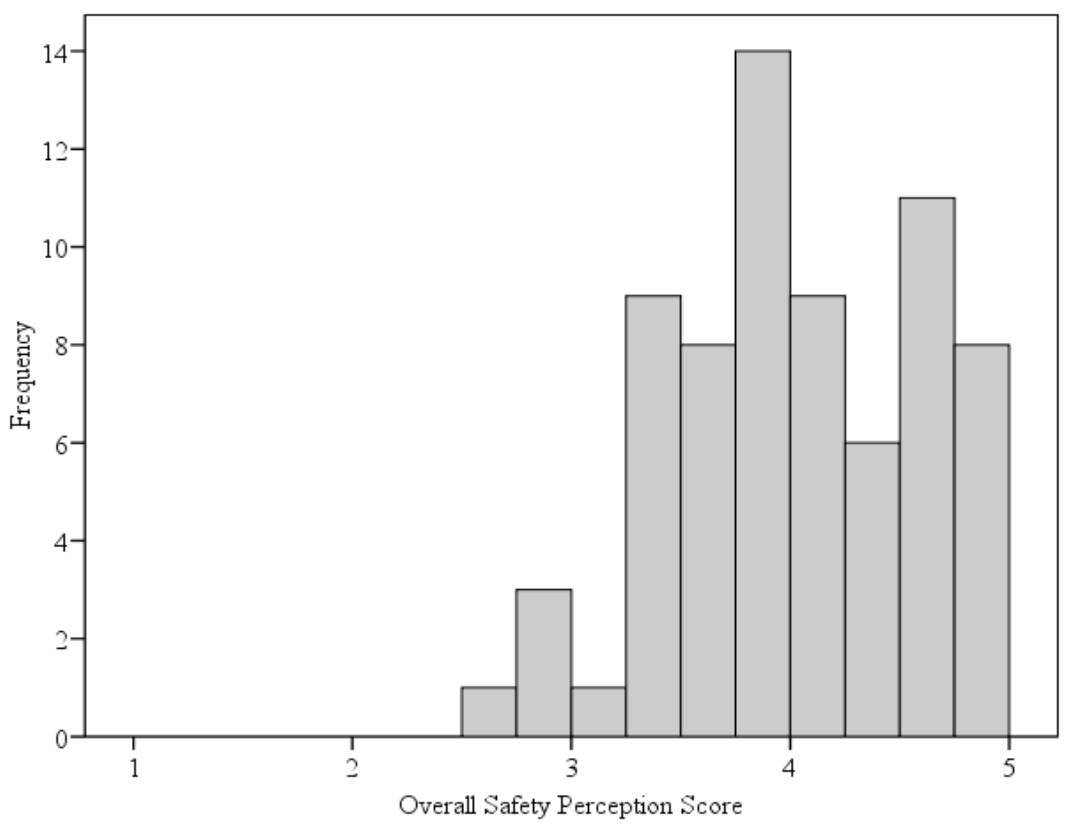

Figure 1. Distribution of Overall Survey Scores: Non-safety group. 
The distribution of the overall safety scores for the non-safety group is illustrated in Figure 1. The histogram in Figure 1 indicates that the distribution was slightly negatively skewed with the bulk of scores falling towards the upper end of the scale (i.e. agree and strongly agree). None of the employees indicated that they had solid disagreement overall and only four employees had scores at or below three.

Figure 2 illustrates the distribution of overall survey scores for the safety group. The histogram in Figure 2 indicates that the scores were negatively skewed with the bulk of scores falling at the upper end of the distribution (i.e. agree and strongly agree).

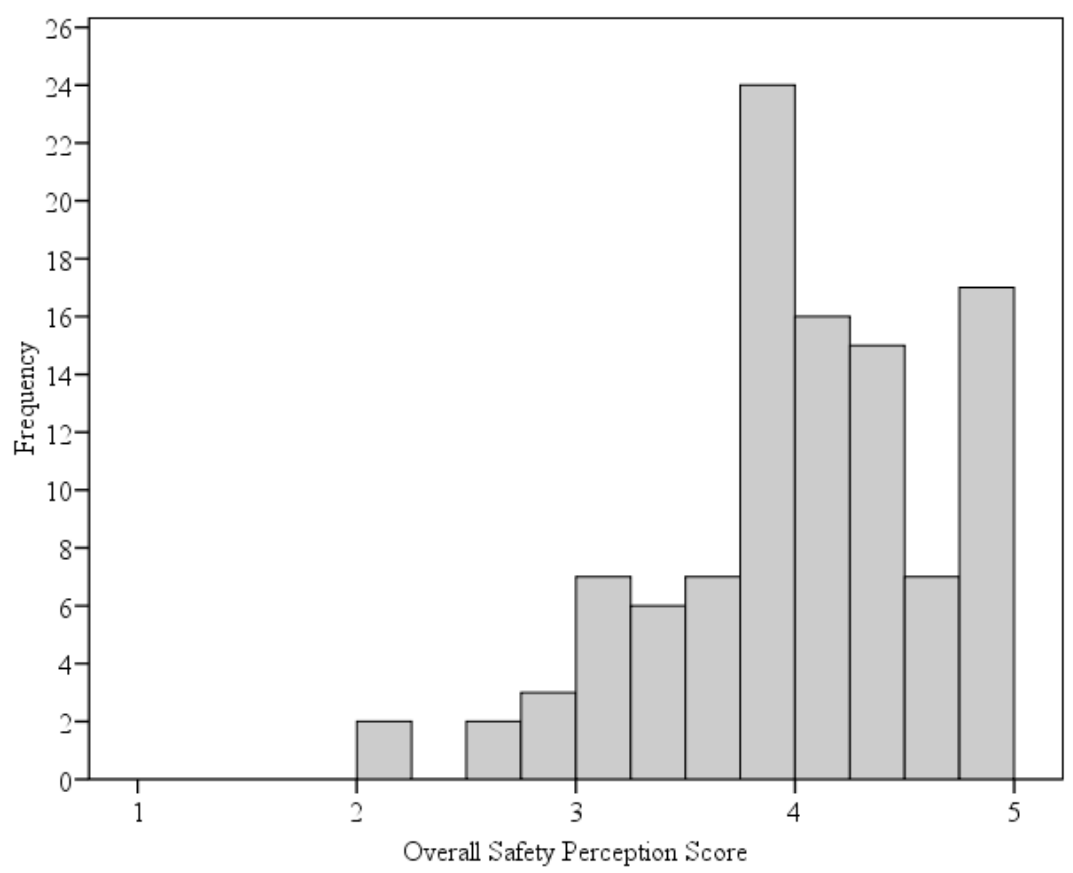

Figure 2. Distribution of Overall Survey Scores: Safety Group.

The distributions in Figures 1 and 2 indicate that the two groups had very similar distributions, although the safety group was more negatively skewed. Therefore, the two groups were similar with regard to their means and their distributions.

\section{Hypothesis One}

The first research hypothesis tested the effect of having a behavioral safety modification process and the effect of race on industrial employees' perceptions of safety. Table 6 provides the overall survey means by group and race. The results in Table 6 indicate that fairly wide differences emerged, although some of the sub-groups had very small sample sizes. Asians in the non-safety group had the most positive overall perceptions (4.44) while Hispanics in the safety group had the least positive overall perceptions (3.55). 
Table 6

Overall Survey Mean by Group and Race

\begin{tabular}{llcc}
\hline Group & Race & $N$ & Mean \\
\hline \multirow{4}{*}{ No Safety } & Asian & 5 & 4.44 \\
& Black & 25 & 3.69 \\
& Hispanic & 3 & 4.09 \\
& White & 36 & 4.15 \\
\hline \multirow{4}{*}{ Safety } & Asian & 18 & 4.17 \\
& Black & 48 & 4.08 \\
& Hispanic & 14 & 3.55 \\
& White & 26 & 3.98 \\
\hline
\end{tabular}

The results of the $2 \times 4$ factorial ANOVA are provided in Table 7 . The results in Table 7 indicate that there was no significant difference between the two groups $[\mathrm{F}(1,167)=1.32, p>.05]$ with regard to their overall perceptions. However, significant differences were found in employee perceptions based on $\operatorname{race}[\mathrm{F}(1,167)=2.85, p$ $<.05]$ and the interaction between group and race $[\mathrm{F}(1,167)=3.90, p<.05]$. Therefore, although significant differences emerged based on race, the differences between the mean ratings provided by the racial groups depended on their group (safety/non-safety).

Table 7

Anova Results: Race

\begin{tabular}{lccccc}
\hline \multicolumn{7}{c}{ Anova Results: Race } & & & \\
Source & Sum of Squares & $d f$ & Mean Square & $F$ & $p$ \\
\hline Group & 0.43 & 1 & 0.43 & 1.32 & 0.25 \\
Race & 2.82 & 3 & 0.94 & 2.85 & 0.04 \\
Group * Race & 3.86 & 3 & 1.29 & 3.90 & 0.01 \\
Error & 55.10 & 167 & 0.33 & & \\
\hline
\end{tabular}

Figure 3 shows the mean ratings by group and race. The results in Figure 3 highlight the significant interaction effect for Hispanics in particular. Hispanics had the largest discrepancy with regard to their mean ratings in the safety group (3.55) versus the non-safety group (4.09). On average, Asians, Hispanics and Whites provided higher ratings if they were in the non-safety group while the opposite was true for Blacks. Interestingly, Asians had the highest mean ratings relative to the other racial groups, regardless of their group. Also, Whites had the most similar ratings between the two groups. 


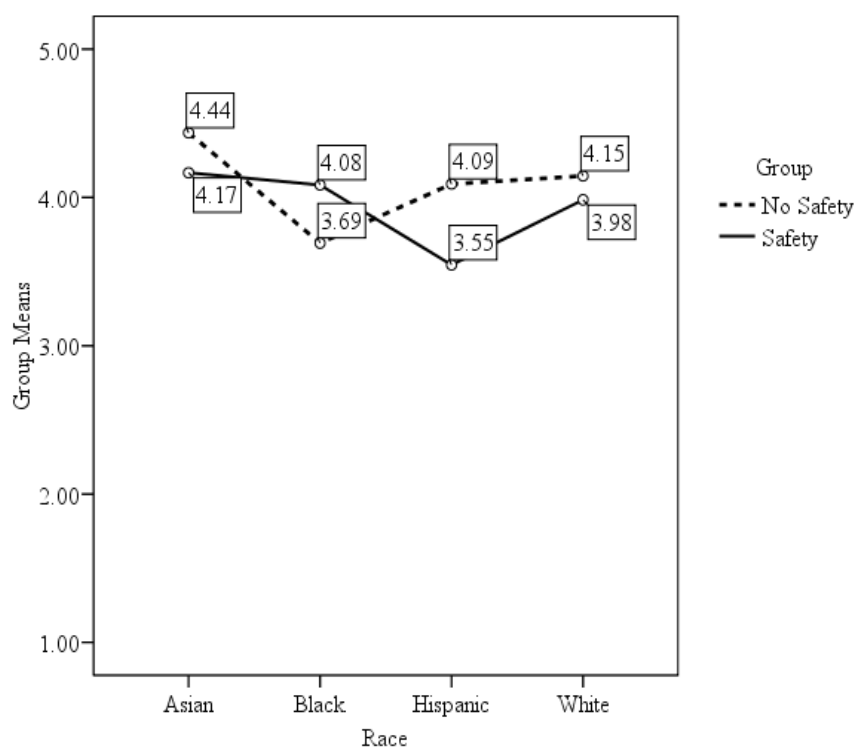

Figure 3. Group Means by Safety Group (yes/no) and Race.

The results for research hypothesis one indicate that race interacts with the effect of having a behavioral safety modification process in the workplace. Not only did differences exist based on race, but the way in which the racial groups differed depended on group. Therefore, research hypothesis one was supported and retained.

\section{Hypothesis Two}

The second research hypothesis tested the effect of having a behavioral safety modification process and the effect of gender on industrial employees' perceptions of safety. Table 8 provides the overall survey means by group and gender. The results in Table 8 indicate that females provided higher ratings regardless of whether or not they were in the safety group. However, females in the safety group provided a much higher mean rating (4.47) than females in the non-safety group (4.07). The mean ratings for males were very similar across the two groups (3.99 vs. 3.97). These results indicate that females in the non-safety group and males (regardless of group) tended to show overall agreement with the safety survey while females in the safety group fell in the middle of agree and strongly agree. Therefore, females in the safety group had the most positive perceptions regarding workplace safety issues, but only seven females were in the safety group.

Table 8

Overall Survey Mean by Group and Gender

\begin{tabular}{llcc} 
Group & Race & $N$ & Mean \\
\hline \multirow{2}{*}{ No Safety } & Female & 18 & 4.07 \\
& Male & 52 & 3.99 \\
\hline \multirow{2}{*}{ Safety } & Female & 7 & 4.47 \\
& Male & 99 & 3.97 \\
\hline
\end{tabular}

The results of the $2 \times 2$ factorial ANOVA are provided in Table 9. The results in Table 9 indicate that there was a statistically significant main effect for gender in that females had statistically significantly higher mean ratings than males regardless of whether or not their organization had a behavioral safety modification process in place 
$[\mathrm{F}(1,172)=4.04, p=.05)$. However, there was no significant effect based on group $[\mathrm{F}(1,172)=1.74, p>.05]$ and there was no significant interaction between group and gender $[\mathrm{F}(1,172)=2.16, p>.05]$.

Table 9

ANOVA Results: Gender

\begin{tabular}{lccccc}
\hline Source & Sum of Squares & $d f$ & Mean Square & $F$ & $p$ \\
\hline Group & 0.63 & 1 & 0.63 & 1.74 & 0.19 \\
Gender & 1.45 & 1 & 1.45 & 4.04 & 0.05 \\
Group * Gender & 0.78 & 1 & 0.78 & 2.16 & 0.14 \\
Error & 61.83 & 172 & 0.36 & & \\
\hline
\end{tabular}

The mean ratings by group and gender are illustrated in Figure 4. The results in Figure 4 indicate that the two lines almost intersect. If they had actually intersected, a significant interaction would have been detected. Also, the figure highlights the fact that the females had substantially higher mean ratings in the safety group than females in the non-safety group and males in general.

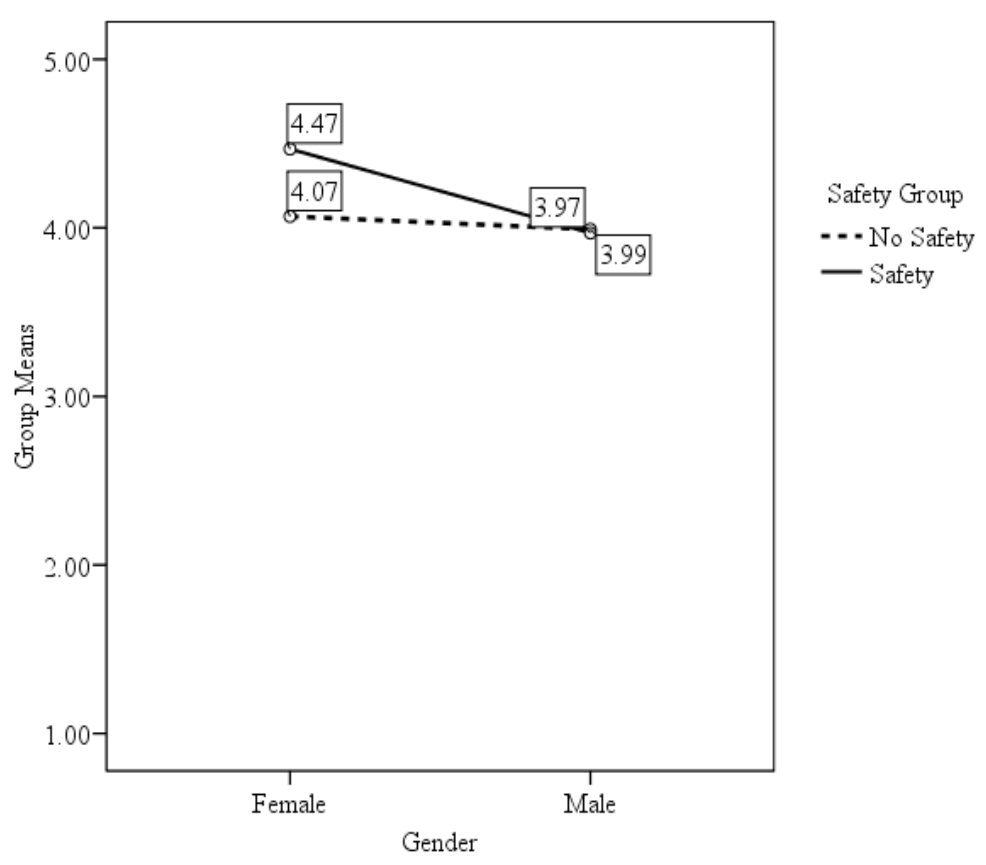

Figure 4. Group Means by Safety Group (yes/no) and Gender.

The results for research hypothesis two indicate that gender does have a significant effect on employee perceptions and, therefore, research hypothesis two was supported and retained. The results also show that females appear to be more sensitive to having a behavioral safety modification process in place than males given the fact that females in the safety group provided very high ratings on average. However, the difference in sensitivity between the two genders did not reach a level of statistical significance.

Hypothesis Three

The third research hypothesis tested the effect of having a behavioral safety modification process and the effect of years of service on industrial employees' perceptions of safety. The number of years of service by safety 
group is presented in Table 10. The results in Table 10 indicate that the two groups were very similar with regard to their ranges, their mean number years of service and their variability. Therefore, the two groups are well matched in terms of years of service.

Table 10

Years of Service by Group

\begin{tabular}{lccccc}
\hline Group & $N$ & Mean & Std. Dev. & Min. & Max \\
\hline No Safety & 70 & 10.50 & 9.08 & 0 & 39 \\
Safety & 106 & 12.54 & 9.15 & 0 & 38 \\
\hline
\end{tabular}

The regression model summary results in Table 11 indicate that the multiple correlation was low $(\mathrm{R}=.18)$ and only $3 \%$ of the differences in employee perceptions can be explained by the cumulative effects of one's safety group (safety/non-safety), one's years of service and the interaction between the two factors. This model did not reach a level of statistical significance $(p>.05)$.

Table 11

Regression Model Summary Results: Years of Service

\begin{tabular}{lccc}
$\mathrm{R}$ & $\mathrm{R}^{2}$ & Adjusted $\mathrm{R}^{2}$ & $p$ \\
\hline 0.18 & 0.03 & 0.02 & 0.13 \\
\hline
\end{tabular}

Although the overall model was not significant, the coefficient results indicate that years of service was statistically significant $(t=-2.38, p<.05)$. The standardized beta weight was negative $(-.29)$ and moderate in strength. Therefore, when controlling for whether or not one belongs to a workplace that has a behavioral safety modification process in place, having fewer years of service was statistically significantly associated with more positive perceptions.

Table 12

Coefficient Results: Years of Service

\begin{tabular}{lccccc}
\hline Source & $B$ & Std. Error & Beta & $t$ & $p$ \\
\hline Constant) & 4.21 & 0.11 & & 38.36 & 0.00 \\
Safety Group & -0.19 & 0.15 & -0.15 & -1.27 & 0.21 \\
Years of Service & -0.02 & 0.01 & -0.29 & -2.38 & 0.02 \\
Interaction Term & 0.02 & 0.01 & 0.27 & 1.71 & 0.09 \\
\hline
\end{tabular}

The results for research hypothesis three indicate that years of service is a significant predictor of employee perceptions. Therefore, research hypothesis three was supported and retained.

The results for race are presented in Figure 8 and indicate that race still has an effect on employee perceptions. The White group was the only racial category that had almost the exact same rating across the two groups (4.15 vs. 4.13). Asians in the non-safety group had a higher mean rating (4.44) than Asians in the safety group (4.01). Blacks in the safety group had a higher mean rating (4.26) than Blacks in the non-safety group (3.69); the difference was substantial. Finally, Hispanics had somewhat similar mean ratings across the two groups (4.09 vs. 3.97); although their mean rating was lower for the safety group. 


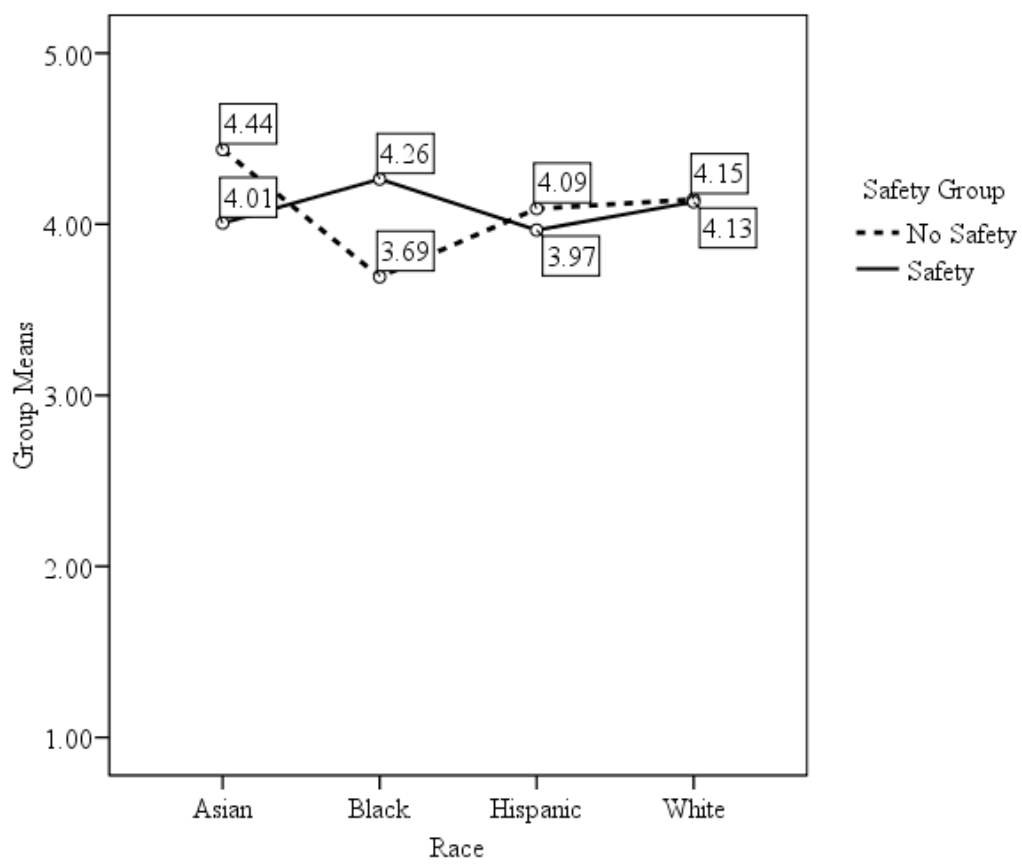

Figure 8. Effect of Race.

The results by gender are illustrated in Figure 9 and indicate that those in the safety group had higher mean ratings than those in the non-safety group, especially for females. Also, females had higher mean ratings than males regardless of group.

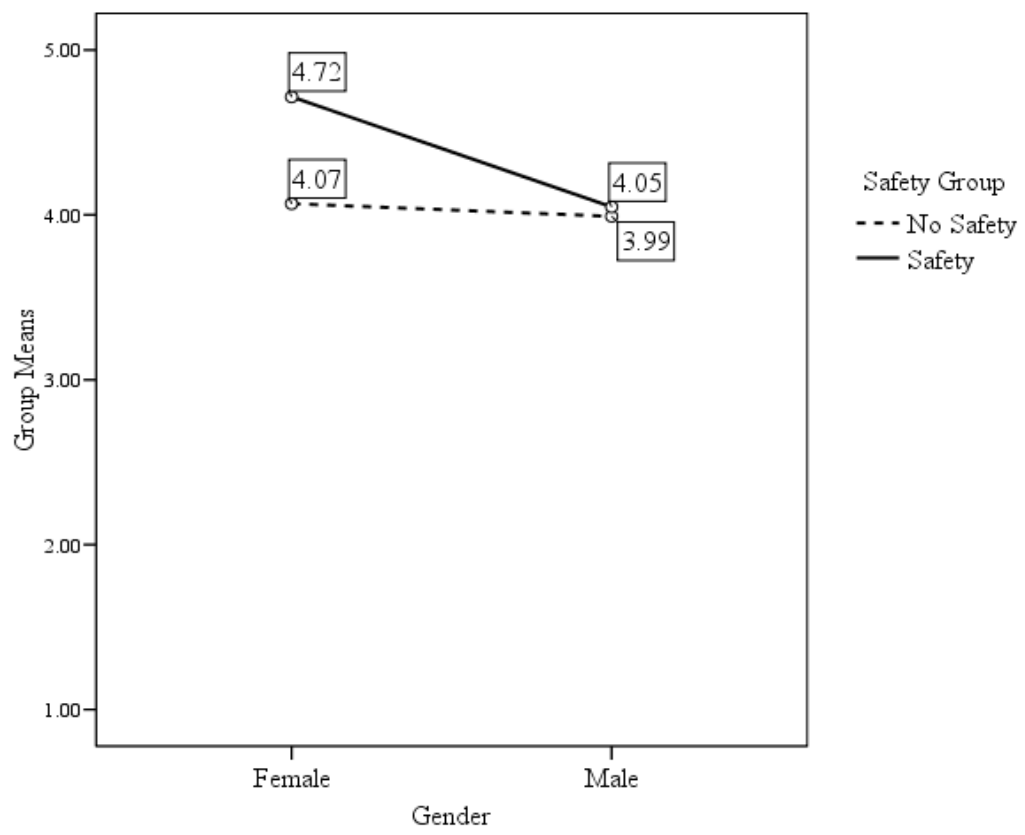

Figure 9. Effect of Gender.

The results for years of service indicate that a relationship exists between years of service and employee perceptions, but the relationship differs based on group. A moderately negative relationship exists between years of 
service and employee perceptions $(r=-.30)$ within the non-safety group. However, a weak relationship exists between years of service and employee perceptions $(r=.11)$ within the safety group.

\section{DISCUSSION AND CONCLUSION}

This research was created to provide the reader with a better understanding of perceptions of safety in an industrial environment, and the affects that race, gender, age, years of service, union membership, and education have on an individual's perception of safety in the workplace when there is a behavioral safety modification process in place.

The following research hypotheses were analyzed:

1. There is a positive increase in industrial employees' perceptions of safety by race when there is a behavioral safety modification process in place in an industrial setting. This hypothesis was supported and retained given the fact that the results indicate that race interacts with the effect of having a behavioral safety modification process in the workplace.

2. There is a positive increase in industrial employees' perceptions of safety by gender when there is a behavioral safety modification process in place in an industrial setting. This hypothesis was supported and retained given the fact that the results indicate that gender has a significant effect on employee perceptions.

3. There is a positive increase in industrial employees' perceptions of safety by years of service when there is a behavioral safety modification process in place in an industrial setting. This hypothesis was supported and retained indicating that years of service is a significant predictor of employee perceptions.

\section{CONCLUSION}

The findings presented in this research provide a broad overview of the industrial safety literature in an attempt to inform, educate, and perhaps stimulate interest among organizational researchers in these relatively under-recognized concepts. The real and potential importance of these constructs and their associated research is quite evident, given the implications of workplace dimensions that interact with individual level factors affecting workers' overall experiences of safety in the workplace.

While some constructs in the organizational sciences are relatively abstract and disconnected from reality, health and safety are clearly linked to the everyday work and life experiences of all organizational members. Thus, this is an obvious area where the concerns and agendas for managers, executives, and care-providers are closely aligned with those of scholars and researchers. That is, the basic questions associated with health and safety that a manager might raise should be of clear interest and relevance to researchers. Likewise, the questions and hypotheses that might be developed from a research program are likely to be of clear and immediate interest to those in organizations. Clearly, then, the concepts of health and safety in the workplace should be elevated to the same degree of importance to organizational leaders as the more commonly studied concepts of leadership, motivation, and attitudes. This research is intended to serve as a catalyst for just such a transition.

\section{AUTHOR INFORMATION}

Dr. Joy Maria Jones is an adjunct professor at the University of Phoenix, teaching classes in Human Resources and Conflict Resolution. She currently works full-time for Smurfit-Stone Container Corporation as a Business Unit Human Resources Manager. She holds a Bachelor of Science in Occupational Safety \& Industrial Hygiene Management, a Master of Science in Human Resources Management, and a Doctoral degree in Business Administration.

Dr. Robert C. Preziosi is a professor of management with the H. Wayne Huizenga School of Business and Entrepreneurship at Nova Southeastern University. He is faculty chair of the Human Resources Management major and developed the school's master's degree in leadership. In December 2000, he was named Professor of the Decade by the school. He is on the Editorial Boards of Employment Relations Today,_Journal of Applied Management and Entrepreneurship, Employee Responsibilities and Rights Journal, and The Journal of Business Case Studies. He 
holds a bachelor's degree in social science, an M.Ed. degree in learning psychology, and management doctoral degree.

\section{REFERENCES}

1. Advisory Committee on the Safety of Nuclear Installations (ACSNI) (1993). Study group on human factors, $3^{\text {rd }}$ report: Organising for safety. London: Her Majesty's Stationary Office.

2. Ammons, R. B. (1956). Effects of knowledge of performance: A survey and tentative theoretical formulation. Journal of General Psychology, 54, 279-299.

3. Annett, J. (1969). Feedback and human behavior. Harmondsworth, UK: Penguin Books.

4. $\quad$ Atkinson, W (2000). Behavior-based safety. Management Review, 45(3), 41-46.

5. Baker, D. B. \& Landrigan, P. J. (1990). Occupational related disorders. The Medical Clinics of North America, 74, 441-460.

6. Bruening, J.C. (1997). Standing at the ready: Charting an ergonomics compliance course. Managing Office Technology, 42, 20-23.

7. Cheyne, A., Cox, S., Oliver, A., \& Tomas, J.M. (1998). Modeling safety climate in the prediction of levels of safety activity. Work and Stress, 12, 255-271.

8. Chhockar, J.S., \& Wallin, J.A., (1984a). Improving safety through applied behavior analysis. Journal of Safety Research, 15, 141-151.

9. Chhockar, J.S., \& Wallin, J.A. (1984b). A field study of the effect of feedback frequency on performance. Journal of Applied Psychology, 69, 524-530.

10. Clarke, S. (1998c). Perceptions of organizational safety: Implications for the development of safety culture. Journal of Organizational Behavior, 20, 185-198.

11. Cooper, D. (1998). Improving safety culture. Chichester, UK: John Wiley.

12. Cooper, M.D. \& Phillips, R.A. (1994). Validation of a safety climate measure. Paper presented at the BPS Occupational Psychology Conference, Birmingham, UK.

13. Cox, S. \& Cox, T. (1991). The structure of employee attitudes to safety: A European example. Work and Stress, 5, 93-106.

14. Cox, S. J., \& Cheyne, A. J. T. (2000). Assessing safety culture in offshore environments. Safety Science, $34,1-3$.

15. Cullen, D. (1990). The public enquiry into the Piper Alpha disaster. London, UK: Her Majesty's Stationary Office.

16. Donald, I., \& Young, S. (1996). Managing safety and attitudinal-based approaches to improving safety in organizations. Leadership \& Organizational Development Journal, 17(4), 17-25.

17. Emmet, E. A. (1991). Physical and chemical agents at the workplace. In G.M. Green \& F. Baker (Eds.), Work, health, and productivity, 35-44. New York, NY: Oxford University Press.

18. Figura, S. Z. (1997). Respiratory disease: An elusive foe. Occupational Hazards, 59, 87-89.

19. Finnegan, L. (1997). NIOSH report links MSDS and workplace risk factors. Occupational Hazards, 59, 16.

20. Frick, K., Jensen, P.J., Quinlan, M., \& Wilthagen, T. (2000). Systematic occupational health and safety management. New York, NY: Pergamon Press.

21. Gadd, S., \& Collins, M. (2002). Safety culture: A review of the literature. Human Factors Group, 1-30.

22. Geller, E., Boyce, T., Williams, J., Pettinger, C., DePasquale, J., \& Clarke, S. (1998). Researching behavior-based safety: A multi-method assessment and evaluation. Paper presented during the Proceedings of the $37^{\text {th }}$ Annual Professional Development Conference and Exposition. Des Plaines, IL.

23. Gray, G. R., Myers, D. W., \& Myers, P. S. (1998). Collective bargaining agreements: Safety and health provisions. Monthly Labor Review, 121, 13.

24. Griffin, M.A., \& Neal, A., (2000a). Perceptions of safety at work: A framework for linking safety climate to safety performance, knowledge, and motivation. Journal of Occupational Health Psychology, 5, 347358.

25. Guldenmund, F.W. (2000). The nature of safety culture: A review of theory and research. Safety Science, 34, 215-257.

26. Hale, A. R., (2000). Culture's confusions. Safety Science, 34, 1-3. 
27. Hart, P. M., Wearing, A. J., Griffin, M. A., \& Cooper, C. L. (1996). Integrating Personal and Organisational Factors into a Coherent Model of Occupational Well-being. Paper presented at the $21^{\text {st }}$ annual meeting of the Academy of Management, Cincinnati, $\mathrm{OH}$.

28. Hart, P. M., Wearing, A. J., Conn, M., Carter, N. L., \& Dingle, R. (2000). Development of the School Organisational Health Questionnaire: A measure for assessing teacher morale and school organizational climate. British Journal of Educational Psychology, 70 (2), 211-228.

29. Hayes, B.E., Peranda, J., Smecko, T., \& Trask, J. (1998). Measuring perceptions of workplace safety: Development and validation of the workplace safety scale. Journal of Safety Research, 29,145-61.

30. Hofstede, G. (1991). Cultures and organizations: Software of the mind. London, UK: McGraw-Hill.

31. Homer, P., \& Kahle, L. (1988). A structural equation test of value-attitude-behavior hierarchy. Journal of Personality and Social Psychology, 54, 638-646.

32. James, L. A., \& James, L. R. (1989). Integrating work environment perceptions: Explorations into the measurement of meaning. Journal of Applied Psychology,74, 739-751.

33. Johnson, P., \& Gill, J. (1993). Management control and organizational behavior. London: Paul Chapman Publishing.

34. Johnson, S. E., (2003). Behavioral theories of safety psychology. Professional Safety, 48(10), 39-43.

35. Komaki, J., Heinzmann, A., \& Lawson, L. (1980). Effect of training feedback: Component analysis of a behavior safety program. Journal of Applied Psychology, 65, 261-270.

36. Krause, T. R., \& Sloat, K. (1993). Attitude alone is not enough. Occupational Health \& Safety, 62, 26.

37. McDonald, N., \& Ryan, F. (1992). Constraints on the development of safety culture: a preliminary analysis. Irish Journal of Psychology, 13, 273-281.

38. Miller, I., \& Cox, S. J. (1997). Benchmarking for loss control. Journal of the Institution of Occupational Safety and Health, 1, 39-47.

39. Mills, D. (1996). The behavioural approach: A program to transfer responsibilities for employees safety behaviours from upper management to the workers themselves can radically alter the safety equation. $O H \&$ Canada, 12, 6 .

40. Moran, E.T., \& Volkwein, J.F. (1992). The cultural approach to the formation of organizational climate. Human Relations, 45, 19-47.

41. Morgan, G. (1986). Images of organization. Beverly Hills, London: Sage.

42. Morgan, G. (1997). Images of organization. New York, NY: Praeger.

43. National Safety Council. (2006). Injury facts, 2005-2006 edition. Itasca, Il: Fearn, K., Hoskin, A., Lin, M., Porretta, K, \& Sinelnikov, S.

44. National Safety Council Safety Statistics. Retrieved November 4, 2004 from www.nationalsafetycouncil.org.

45. Neal, A., Griffin, M. A., \& Hart, P. M. (2000). The impact of organizational climate on safety climate and individual behavior. Safety Science, 34, 99-109.

46. Parker, S.K., Axtell, C.M., \& Turner, N. (2001). Designing a safer workplace: Importance of job autonomy, communication, quality, and supportive supervisors. Journal of Occupational Health Psychology, 6(3), 211-228.

47. Sassenrath, J. M. (1975). Theory and results on feedback and retention. Journal of Educational Psychology, 67(6), 894-899.

48. Schein, E. H. (1984). Coming to a new awareness of organizational culture. Sloan Management Review, 25, 3-14.

49. Schein, E.H. (1985). Organizational culture and leadership. San Francisco, CA: Jossey Bass.

50. Schein, E.H. (1992). Organizational culture and leadership ( $2^{\text {nd }}$ ed.). San Francisco, CA: Jossey Bass.

51. Schein, E. H., \& Ott, J.B. (1962). The legitimacy of the organizational influences. American Journal of Sociology, 67, 682-689.

52. Schwartz, H., \& Davis, S. (1981). Matching corporate culture and business strategy. Organizational Dynamics, 10, 30-38.

53. Skov, T., Borg, V., \& Orheda, E. (1996). Psycholosocial and physical risk factors for musculoskeletal disorders of the neck, shoulders, and lower back in sales people. Occupational and Environmental Medicine, 53, 351-356.

54. Smircich, L. (1983). Concept of culture and organizational analysis. Administrative Science Quarterly, 28(3), 339-359. 
55. Zohar, D. (1980). Safety climate in industrial organizations: theoretical and applied implications. Journal of Applied Psychology, 65, 96-102.

\section{NOTES}

